Special issue of the 3rd International Conference on Computational and Experimental Science and Engineering (ICCESEN 2016)

\title{
Experimental and Quantum Chemical Calculations of
} 2-Amino-4,5,6,7-Tetrahydrobenzo[b]Thiophene-3-Carbonitrile

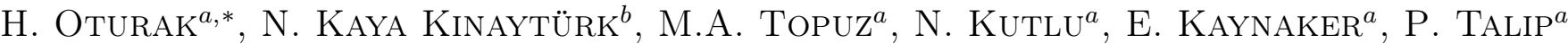 \\ AND Y. SERT ${ }^{c}$ \\ ${ }^{a}$ Süleyman Demirel University, Physics Department, Isparta, Turkey \\ ${ }^{b}$ Süleyman Demirel University, Experimental and Observational Research and Application Centre, Isparta, Turkey \\ ${ }^{c}$ Department of Physics, Faculty of Art and Sciences, Bozok University, Yozgat 66100, Turkey
}

\begin{abstract}
Vibrational frequencies of 2-Amino-4,5,6,7-Tetrahydrobenzo[b]Thiophene-3-Carbonitrile were calculated using density functional (DFT/B3YLP) method with $6-311++\mathrm{G}(\mathrm{d}, \mathrm{p})$ basis set by Gaussian 09. The assignments of the vibrational frequencies have been done by potential energy distribution analysis, using VEDA 4 software. The density functional theory and time dependent density functional theory methods have been used to study the electronic properties of 2-Amino-4,5,6,7-Tetrahydrobenzo[b]Thiophene-3-Carbonitrile. Isotropic chemical shifts were calculated using the gauge-invariant atomic orbital method. All computed spectroscopic properties were compared with experimental ones. The simulated spectra of the molecule show excellent agreement with the experimental spectra.
\end{abstract}

DOI: 10.12693/APhysPolA.132.1192

PACS/topics: 31.15.E-, 33.20.Ea, 33.20.Tp, 33.20.Fb, 33.20.Lg, 33.20.Bx

\section{Introduction}

Thiophene is one of the simplest aromatic molecules with a five membered heterocyclic sulphur-containing ring. Thiophene obeyes the $4 n+2 \pi$ electron rule and is considered to be aromatic. Thiophene is uniquely an electron rich heterocycle and has the highest resonance stabilization energy among the five membered heterocycles. Thiophenes are part of many organic compounds having vast applications in the field of electronics and optoelectronics, medicine and materials.

The compounds, containing a thiophene ring in their structure have a remarkable pharmacological efficiency. They are known for their antidepressant, anticonvulsant, anthelmintic, antispasmodic, antihistaminic, anesthetic, antipruritic, antitussive and analgesic action. Thiophene and its derivatives exhibit diverse biological properties, such as nemoticial, insecticidal, antibacterial, antifungal, antiviral and antioxidant activity [1-15].

The molecular structure of the title compound, 2-Amino-4,5,6,7-Tetrahydrobenzo[b]Thiophene-3-Carbonitrile (ATHBTCN), has been studied by single crystal X-ray spectroscopy [1]. Although X-ray diffraction method is one of the most frequently applied techniques for structural characterization of pharmaceutical compounds, the use of vibrational spectroscopy is also gaining increasing attention. X-ray diffraction techniques are sensible to the long range order while vibrational spectroscopy (IR and Raman) is applicable to the short-range structure of molecular solids. As the

*corresponding author; e-mail: haliloturak@sdu.edu.tr literature survey reveals, neither IR and Raman spectra nor quantum chemical calculations of the compound have been reported so far. Hence the present work was undertaken to study the vibrational spectra by quantum chemical calculations. We have interpreted the calculated spectra in terms of potential energy distribution (PED).

\section{Experimental and computation details}

The compounds of ATHBTCN in solid form were purchased from Sigma-Aldrich chemical company (U.S.A.) with a purity of greater than $98 \%$, and were used as such, without further purification. The FT-IR spectrum was recorded using $\mathrm{KBr}$ pellets on a Perkin Elmer Spectrum BX FTIR spectrophotometer in the region of 4000 $400 \mathrm{~cm}^{-1}$. The FT-Raman spectrum was obtained on a DXR-Raman Microscope in the region of 3500-12 $\mathrm{cm}^{-1}$. The ${ }^{1} \mathrm{H}$ and ${ }^{13} \mathrm{C}$ NMR were taken in DMSO solutions on a Bruker Ultrashield 400 Plus NMR spectrometer. Proton and carbon signals were referenced to TMS. UV-visible spectroscopy analyses were carried out using a Perkin Elmer Lambda 20 spectrofotometer. All spectra were measured at room temperature.

Gaussian 09 [16] software package was used for the theoretical calculations. The quantum chemical calculations were performed by applying the density functional theory (DFT) method, with the B3LYP functional and the $6-311 \mathrm{G}++(\mathrm{d}, \mathrm{p})$ basis set. Since B3LYP vibrational wavenumbers are known to be higher than the experimental wavenumbers due to neglect of anharmonicity effects, they were scaled down by a uniform scaling factor of 0.983 for wavenumbers up to $1700 \mathrm{~cm}^{-1}$ and 0.958 for wavenumbers greater than $1700 \mathrm{~cm}^{-1}$ [17]. The scaled wavenumbers in general show good agreement with experimental ones. 
The geometry optimizations were followed by frequency calculations using the same basis set. The same basis set and functional were also used for the calculations of ${ }^{1} \mathrm{H}$ and ${ }^{13} \mathrm{C}$ NMR shielding constants, by applying the GIAO method. UV-Vis spectra and electronic properties were determined by time-dependent DFT (TD-DFT). The results were visualized using Gauss View program [18]. Initial atomic coordinates can be generally taken from any database or experimental XRD results. We have used the experimental XRD data and Gauss View software database to determine the initial atomic coordinates and to optimize the input structure. After the optimization, we have used the most stable optimized structure for further theoretical analysis.

In this study, initial atomic coordinates that were taken from Gauss View database [18] have given most stable structure after optimization. Total energy distribution corresponding to the observed frequencies was calculated using VEDA 4 program [19].

\section{Results and discussion}

\subsection{Geometric structure}

The single $\mathrm{X}$-ray crystallographic analysis of the title compound $\left(\mathrm{C}_{9} \mathrm{H}_{10} \mathrm{~N}_{2} \mathrm{~S}\right)$ shows that its crystal belongs to space group $P 2_{1} / c$ and belongs to monoclinic system with the following cell dimensions: $a=10.4274 \AA$, $b=8.1487 \AA, c=13.2342 \AA, \beta=126.937^{\circ}$ and $V=898.81 \AA^{3}$ [1]. The theoretical and experimental structure parameters (bond lengths, bond angles and torsion angles) are shown in Table I, in accordance with the atom-numbering scheme, given in Fig. 1.

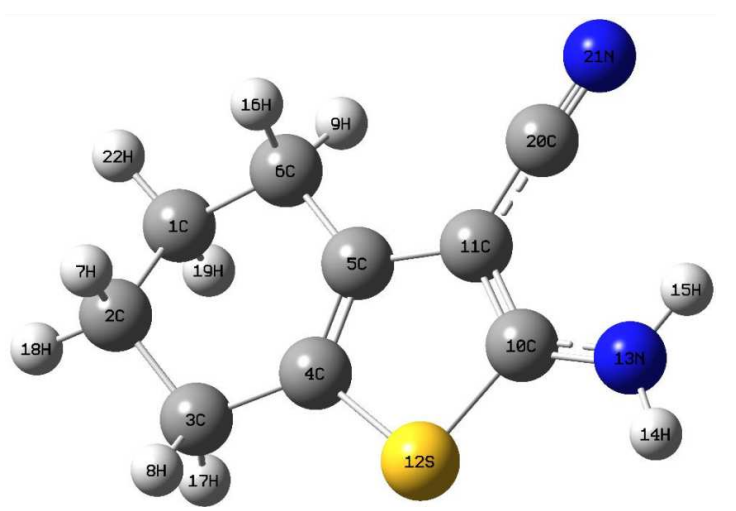

Fig. 1. Optimized structure of ATHBTCN.

When we look at the key data for our compound: in carbonitrile group, C11-C20 and C20 $\equiv \mathrm{N} 21$ bond lengths have been recorded as $1.417 \AA$ and $1.145 \AA$, respectively. These bond lengths have been calculated as $1.4132 \AA$ and $1.1598 \AA$, respectively by B3LYP method. In thiophene ring $\mathrm{C} 4-\mathrm{S} 12$ and $\mathrm{C} 10-\mathrm{S} 12$ bond lengths have been reported as $1.7432 \AA$ and $1.7280 \AA$, respectively. These data have been calculated as $1.7691 \AA$ and $1.7462 \AA$, respectively. Finally, $\mathrm{C} 5=\mathrm{C} 4$ bond length has been observed as $1.346 \AA$. We have calculated this length as $1.366 \AA$ with B3LYP method.
TABLE I

Optimized parameters of ATHBTCN.

\begin{tabular}{|c|c|c|}
\hline Parameters & X-ray [1] & B3LYP $6311++\mathrm{G}(\mathrm{d}, \mathrm{p})$ \\
\hline \multicolumn{3}{|c|}{ Bond lengths } \\
\hline $\mathrm{S} 12-\mathrm{C} 10$ & 1.728 & 1.7462 \\
\hline $\mathrm{S} 12-\mathrm{C} 4$ & 1.743 & 1.7691 \\
\hline $\mathrm{N} 21-\mathrm{C} 20$ & 1.145 & 1.1598 \\
\hline N13-C10 & 1.351 & 1.3612 \\
\hline N13-H14 & 0.860 & 1.0039 \\
\hline N13-H15 & 0.860 & 1.0073 \\
\hline $\mathrm{C} 11-\mathrm{C} 10$ & 1.383 & 1.3855 \\
\hline $\mathrm{C} 11-\mathrm{C} 20$ & 1.417 & 1.4132 \\
\hline C11-C5 & 1.438 & 1.4480 \\
\hline C5-C4 & 1.346 & 1.3665 \\
\hline $\mathrm{C} 5-\mathrm{C} 6$ & 1.502 & 1.5066 \\
\hline $\mathrm{C} 6-\mathrm{C} 1$ & 1.530 & 1.5375 \\
\hline C6-H9 & 0.9700 & 1.0947 \\
\hline C6-H16 & 0.9700 & 1.0978 \\
\hline $\mathrm{C} 1-\mathrm{C} 2$ & 1.509 & 1.5351 \\
\hline C1-H19 & 0.970 & 1.0965 \\
\hline $\mathrm{C} 1-\mathrm{H} 22$ & 0.970 & 1.0937 \\
\hline $\mathrm{C} 2-\mathrm{C} 3$ & 1.526 & 1.5351 \\
\hline $\mathrm{C} 2-\mathrm{H} 7$ & 0.970 & 1.0961 \\
\hline $\mathrm{C} 2-\mathrm{H} 18$ & 0.970 & 1.0938 \\
\hline $\mathrm{C} 3-\mathrm{C} 4$ & 1.502 & 1.5014 \\
\hline $\mathrm{C} 3-\mathrm{H} 8$ & 0.970 & 1.0953 \\
\hline C3-H17 & 0.9700 & 1.0981 \\
\hline \multicolumn{3}{|c|}{ Bond angles $\left[{ }^{\circ}\right]$} \\
\hline $\mathrm{C} 10-\mathrm{S} 12-\mathrm{C} 4$ & 92.09 & 91.6901 \\
\hline C10-N13-H14 & 120.0 & 121.8968 \\
\hline C10-N13-H15 & 120.0 & 119.7581 \\
\hline $\mathrm{H} 14-\mathrm{N} 13-\mathrm{H} 15$ & 120.0 & 118.3448 \\
\hline $\mathrm{C} 10-\mathrm{C} 11-\mathrm{C} 20$ & 121.99 & 121.3968 \\
\hline $\mathrm{C} 10-\mathrm{C} 11-\mathrm{C} 5$ & 113.48 & 113.0574 \\
\hline $\mathrm{C} 20-\mathrm{C} 11-\mathrm{C} 5$ & 124.47 & 125.5452 \\
\hline $\mathrm{C} 4-\mathrm{C} 5-\mathrm{C} 11$ & 112.23 & 113.0603 \\
\hline $\mathrm{C} 4-\mathrm{C} 5-\mathrm{C} 6$ & 122.47 & 122.1610 \\
\hline C11-C5-C6 & 125.29 & 124.7771 \\
\hline $\mathrm{C} 5-\mathrm{C} 6-\mathrm{C} 1$ & 110.43 & 111.2581 \\
\hline C5-C6-H9 & 109.6 & 109.9205 \\
\hline C1-C6-H9 & 109.6 & 110.3649 \\
\hline C5-C6-H16 & 109.6 & 109.2059 \\
\hline C1-C6-H16 & 109.6 & 110.0731 \\
\hline H9-C6-H16 & 108.1 & 105.8717 \\
\hline $\mathrm{C} 2-\mathrm{C} 1-\mathrm{C} 6$ & 111.65 & 111.6692 \\
\hline $\mathrm{C} 2-\mathrm{C} 1-\mathrm{H} 19$ & 109.3 & 109.1527 \\
\hline C6-C1-H19 & 109.3 & 109.2828 \\
\hline $\mathrm{C} 2-\mathrm{C} 1-\mathrm{H} 22$ & 109.3 & 110.2162 \\
\hline $\mathrm{C} 6-\mathrm{C} 1-\mathrm{H} 22$ & 109.3 & 109.6786 \\
\hline H19-C4-H22 & 108.0 & 106.7088 \\
\hline $\mathrm{C} 1-\mathrm{C} 2-\mathrm{C} 3$ & 111.88 & 111.5164 \\
\hline $\mathrm{C} 1-\mathrm{C} 2-\mathrm{H} 7$ & 109.2 & 109.2407 \\
\hline $\mathrm{C} 3-\mathrm{C} 2-\mathrm{H} 7$ & 109.2 & 109.1132 \\
\hline $\mathrm{C} 1-\mathrm{C} 2-\mathrm{H} 18$ & 109.2 & 110.4469 \\
\hline C3-C2-H19 & 109.2 & 109.4775 \\
\hline
\end{tabular}


TABLE I cont.

Optimized parameters of ATHBTCN.

\begin{tabular}{c|c|c}
\hline \hline Parameters & X-ray [1] & B3LYP 6311++G(d,p) \\
\hline \multicolumn{3}{|c}{ Bond angles [ $\left.{ }^{\circ}\right]$} \\
\hline H7-C2-H19 & 107.9 & 106.9275 \\
C4-C3-C2 & 109.33 & 109.5923 \\
C4-C3-H8 & 109.8 & 110.8944 \\
C2-C3-H8 & 109.8 & 109.9175 \\
C4-C3-H17 & 109.8 & 110.2467 \\
C2-C3-H17 & 109.8 & 109.8390 \\
H8-C3-H17 & 108.3 & 106.3030 \\
C5-C4-C3 & 125.82 & 126.2009 \\
C5-C4-S12 & 111.97 & 111.3386 \\
C3-C4-S12 & 122.20 & 122.4987 \\
N13-C10-C11 & 128.53 & 127.5120 \\
N13-C10-S12 & 121.26 & 121.6358 \\
C11-C10-S12 & 110.21 & 110.8521 \\
N21-C20-C11 & 178.84 & 177.7332 \\
& &
\end{tabular}

Similarly, when we look at the key bond angle data: C4-S12-C10, S12-C10-N13 and C5-C11-C20 have been reported as $92.09^{\circ}, 121.26^{\circ}$ and $124.47^{\circ}$, respectively. We have calculated these angles as $91.6901^{\circ}, 121.6358^{\circ}$ and $125.5452^{\circ}$, respectively.

\subsection{Vibrational analysis}

The experimental FT-IR and FT-Raman spectra of the title compound are compared with the theoretical spectra in Figs. 2 and 3, respectively. The scaled calculated harmonic vibrational frequencies at B3LYP level, observed vibrational frequencies, and detailed PED assignments are tabulated in Table II. Harmonic frequencies are calculated for gas phase of an isolated compound, although the experimental ones are obtained for its solid phase. Therefore, there is a disagreement between the observed and calculated frequencies in some modes.

TABLE II

Detailed assignments of experimental and theoretical wavenumbers of ATHBTCN, along with potential energy distribution.

\begin{tabular}{|c|c|c|c|c|}
\hline \multicolumn{2}{|c|}{ DFT-B3LYP-6311++G(d,p) } & \multicolumn{2}{|c|}{ Experimental } & \multirow[t]{2}{*}{ Assignment } \\
\hline non-scaled & scaled & IR & Raman & \\
\hline 3737 & 3561 & 3445 & 3444 & $\nu_{\mathrm{NH}}(97)$ \\
\hline 3609 & 3439 & 3327 & 3326 & $\nu_{\mathrm{NH}}(97)$ \\
\hline 3068 & 2924 & 2956 & & $\nu_{\mathrm{CH}}(93)$ \\
\hline 3065 & 2921 & 2930 & 2936 & $\nu_{\mathrm{CH}}(98)$ \\
\hline 3051 & 2908 & 2909 & 2912 & $\nu_{\mathrm{CH}}(92)$ \\
\hline 3040 & 2897 & & 2889 & $\nu_{\mathrm{CH}}(87)$ \\
\hline 3021 & 2879 & & & $\nu_{\mathrm{CH}}(85)$ \\
\hline 3014 & 2872 & & 2868 & $\nu_{\mathrm{CH}}(88)$ \\
\hline 3004 & 2863 & 2853 & & $\nu_{\mathrm{CH}}(91)$ \\
\hline 2995 & 2854 & 2836 & 2838 & $\nu_{\mathrm{CH}}(98)$ \\
\hline 2297 & 2189 & 2197 & 2196 & $\nu_{\mathrm{NC}}(88)+\nu_{\mathrm{CC}}(12)$ \\
\hline 1650 & 1581 & 1616 & 1618 & $\delta_{\mathrm{HNH}}(86)$ \\
\hline 1626 & 1558 & 1590 & 1589 & $\nu_{\mathrm{CC}}(83)$ \\
\hline 1546 & 1481 & 1521 & 1518 & $\nu_{\mathrm{CC}}(53)+\nu_{\mathrm{NC}}(24)$ \\
\hline 1502 & 1439 & 1444 & 1446 & $\delta_{\mathrm{HCH}}(88)$ \\
\hline 1492 & 1429 & 1433 & & $\delta_{\mathrm{HCH}}(87)$ \\
\hline 1489 & 1426 & & 1429 & $\delta_{\mathrm{HCH}}(84)$ \\
\hline 1479 & 1417 & 1399 & & $\delta_{\mathrm{HCH}}(81)$ \\
\hline 1423 & 1363 & & 1399 & $\nu_{\mathrm{CC}}(31)+\tau_{\mathrm{HCCC}}(10)$ \\
\hline 1382 & 1324 & 1339 & 1333 & $\delta_{\mathrm{HCC}}(10)+\tau_{\mathrm{HCCC}}(60)$ \\
\hline 1371 & 1313 & 1330 & & $\tau_{\mathrm{HCCC}}(61)$ \\
\hline 1367 & 1310 & & & $\delta_{\mathrm{HCC}}(37)+\tau_{\mathrm{HCCC}}(22)$ \\
\hline 1360 & 1303 & 1282 & & $\nu_{\mathrm{CC}}(11)+\tau_{\mathrm{HCCC}}(20)$ \\
\hline 1311 & 1256 & 1251 & 1255 & $\nu_{\mathrm{NC}}(16)+\nu_{\mathrm{CC}}(12)+\delta_{\mathrm{HCC}}(27)$ \\
\hline 1282 & 1228 & 1235 & & $\delta_{\mathrm{HCC}}(22)+\tau_{\mathrm{HCCC}}(25)$ \\
\hline 1269 & 1216 & & 1197 & $\delta_{\mathrm{HCC}}(48)+\tau_{\mathrm{HCCC}}(11)+\tau_{\mathrm{CCCC}}(13)$ \\
\hline 1204 & 1153 & 1164 & 1168 & $\mathrm{n}_{\mathrm{CC}}(11)+\delta_{\mathrm{HNC}}(12)+\tau_{\mathrm{HCCC}}(12)$ \\
\hline 1187 & 1137 & 1127 & & $\delta_{\mathrm{HNC}}(18)+\tau_{\mathrm{HCCC}}(31)$ \\
\hline 1163 & 1114 & & 1129 & $\delta_{\mathrm{HCC}}(66)$ \\
\hline
\end{tabular}


TABLE II cont.

Detailed assignments of experimental and theoretical wavenumbers of ATHBTCN, along with potential energy distribution.

\begin{tabular}{|c|c|c|c|c|}
\hline \multicolumn{2}{|c|}{ DFT-B3LYP-6311++G(d,p) } & \multicolumn{2}{|c|}{ Experimental } & \multirow[t]{2}{*}{ Assignment } \\
\hline non-scaled & scaled & IR & Raman & \\
\hline 1132 & 1084 & 1063 & & $\nu_{\mathrm{CC}}(21)+\delta_{\mathrm{HNC}}(27)$ \\
\hline 1101 & 1055 & & & $\delta_{\mathrm{HCC}}(24)+\tau_{\mathrm{CCCC}}(35)$ \\
\hline 1079 & 1034 & 1023 & & $\nu_{\mathrm{CC}}(51)+\delta_{\mathrm{CCC}}(12)+\tau_{\mathrm{HCCC}}(11)$ \\
\hline 1025 & 982 & 971 & & $\delta_{\mathrm{CCC}}(16)+\tau_{\mathrm{HCCC}}(13)$ \\
\hline 982 & 941 & 949 & & $\nu_{\mathrm{CC}}(50)$ \\
\hline 959 & 919 & & & $\nu_{\mathrm{CC}}(19)+\delta_{\mathrm{CCC}}(28)$ \\
\hline 918 & 879 & 852 & 851 & $\tau_{\mathrm{HCCC}}(46)+\tau_{\mathrm{CCCC}}(16)$ \\
\hline 853 & 817 & 818 & 821 & $\nu_{\mathrm{CC}}(43)$ \\
\hline 834 & 799 & & & $\delta_{\mathrm{HCC}}(15)+\tau_{\mathrm{HCCC}}(51)+\tau_{\mathrm{CCCC}}(12)$ \\
\hline 826 & 791 & 765 & & $\nu_{\mathrm{SC}}(20)+\delta_{\mathrm{HNC}}(10)+\delta_{\mathrm{CCC}}(12)$ \\
\hline 769 & 737 & & & $\nu_{\mathrm{SC}}(12)+\delta_{\mathrm{SCC}}(12)+\delta_{\mathrm{CCC}}(10)+\tau_{\mathrm{HCCC}}(12)$ \\
\hline 672 & 644 & 657 & & $\tau_{\mathrm{NCCC}}(14)+\gamma_{\mathrm{CCCC}}(36)+\gamma_{\mathrm{NCSC}}(18)$ \\
\hline 614 & 588 & & 606 & $\nu_{\mathrm{CC}}(25)+\delta_{\mathrm{CCC}}(11)$ \\
\hline 560 & 536 & 547 & 556 & $\nu_{\mathrm{SC}}(17)+\delta_{\mathrm{NCC}}(16)+\delta_{\mathrm{CCC}}(12)+\gamma_{\mathrm{CCCC}}(12)$ \\
\hline 551 & 528 & & 495 & $\tau_{\mathrm{HCCC}}(14)$ \\
\hline 544 & 521 & 497 & 468 & $\delta_{\mathrm{CCC}}(12)+\tau_{\mathrm{HCCC}}(14)+\gamma_{\mathrm{CCCC}}(15)$ \\
\hline 497 & 476 & 472 & 453 & $\tau_{\mathrm{NCCC}}(61)+\gamma_{\mathrm{NCSC}}(22)$ \\
\hline 470 & 450 & 450 & 403 & $\nu_{\mathrm{CC}}(15)+\nu_{\mathrm{SC}}(16)+\delta_{\mathrm{SCC}}(39)$ \\
\hline 454 & 435 & & 382 & $\nu_{\mathrm{CC}}(15)+\delta_{\mathrm{CCC}}(38)$ \\
\hline 404 & 387 & & & $\delta_{\mathrm{NCC}}(18)+\delta_{\mathrm{CCC}}(18)+\delta_{\mathrm{NCS}}(25)$ \\
\hline 382 & 366 & & 306 & $\delta_{\mathrm{CCC}}(28)+\delta_{\mathrm{NCS}}(22)$ \\
\hline 345 & 331 & & & $\tau_{\mathrm{HNCC}}(94)$ \\
\hline 326 & 312 & & & $\tau_{\mathrm{HNCC}}(63)+\tau_{\mathrm{CCCC}}(10)$ \\
\hline 296 & 284 & & & $\delta_{\mathrm{CCC}}(18)+\tau_{\mathrm{HNCC}}(18)+\tau_{\mathrm{HCCC}}(19)+\tau_{\mathrm{CCCC}}(10)$ \\
\hline 293 & 281 & & & $\tau_{\mathrm{HCCC}}(11)+\tau_{\mathrm{CCCC}}(22)+\tau_{\mathrm{SCCC}}(12)+\gamma_{\mathrm{NCSC}}(17)$ \\
\hline 241 & 231 & & 223 & $\delta_{\mathrm{CCC}}(34)+\delta_{\mathrm{NCS}}(32)$ \\
\hline 213 & 204 & & & $\tau_{\mathrm{HCCC}}(11)+\tau_{\mathrm{CCCC}}(20)+\gamma_{\mathrm{CCCC}}(20)+\gamma_{\mathrm{NCSC}}(11)$ \\
\hline 160 & 153 & & 157 & $\tau_{\mathrm{CCCC}}(18)+\tau_{\mathrm{SCCC}}(49)$ \\
\hline 113 & 108 & & & $\delta_{\mathrm{NCC}}(37)+\delta_{\mathrm{CCC}}(54)$ \\
\hline 96 & 92 & & & $\tau_{\mathrm{CCCC}}(24)+\gamma_{\mathrm{CCCC}}(42)$ \\
\hline 89 & 85 & & & $\tau_{\mathrm{CCCC}}(41)+\gamma_{\mathrm{CCCC}}(20)$ \\
\hline
\end{tabular}

In order to introduce the detailed vibrational assignments of the compound, the PED analysis has been carried out and results are given in Table II. All calculated modes are numbered from the largest to the smallest frequency, within each fundamental wave number, in the Table II.

\subsubsection{Thiophene vibrations}

The $\mathrm{C}-\mathrm{S}$ bands cannot be distinguished in thiophenes. This fact can be explained due to the shorter bond length and higher polarity of the $\mathrm{C}-\mathrm{S}$ bond in thiophenes [20]. Klots et al. [21] assigned this mode at $872 \mathrm{~cm}^{-1}$, $753 \mathrm{~cm}^{-1}$ and $870 \mathrm{~cm}^{-1} ; 750 \mathrm{~cm}^{-1}$ to vapor and liquid phases, respectively. The $\mathrm{C}-\mathrm{S}$ stretching mode is predicted at $691 \mathrm{~cm}^{-1}, 707 \mathrm{~cm}^{-1}$ and recorded at $743 \mathrm{~cm}^{-1}$ and $771 \mathrm{~cm}^{-1}[22]$.

In this work, the $\mathrm{C}-\mathrm{S}$ stretching modes were observed in FT-IR and FT-Raman spectra at $765 \mathrm{~cm}^{-1}$ (IR),
$547 / 556 \mathrm{~cm}^{-1}$ (FT-IR/FT-Raman) and $450 / 403 \mathrm{~cm}^{-1}$ (FT-IR/FT-Raman). These modes (scaled) have been calculated to be at $791 \mathrm{~cm}^{-1}, 737 \mathrm{~cm}^{-1}, 536 \mathrm{~cm}^{-1}$ and $450 \mathrm{~cm}^{-1}$ by DFT/B3LYP method with $6-311++\mathrm{G}(\mathrm{d}, \mathrm{p})$ basis set.

In plane bending modes: $\delta_{\mathrm{SCC}}$ was calculated at $737 \mathrm{~cm}^{-1}$ by scaled B3LYP, but this mode was not observed neither in FT-IR, nor in FT-Raman spectra. Also, $\delta_{\mathrm{SCC}}$ bending modes were seen at $306 \mathrm{~cm}^{-1}$ and $223 \mathrm{~cm}^{-1}$ in FT-Raman spectrum. These modes were calculated to be at $387 \mathrm{~cm}^{-1}, 366 \mathrm{~cm}^{-1}$ and $231 \mathrm{~cm}^{-1}$ by scaled B3LYP method.

Out-of-plane modes: $\gamma_{\mathrm{NCSC}}$ were observed at $657 \mathrm{~cm}^{-1}$ (FT-IR), $472 \mathrm{~cm}^{-1} / 453 \mathrm{~cm}^{-1}$ (FT-IR/FT-Raman), respectively. These modes were calculated to be at $644 \mathrm{~cm}^{-1}, 476 \mathrm{~cm}^{-1}, 281 \mathrm{~cm}^{-1}$ and $204 \mathrm{~cm}^{-1}$ by scaled B3LYP. Other out-of-plane modes are $\tau_{\mathrm{SCCC}}$. These modes were observed at $157 \mathrm{~cm}^{-1}$ in FT-Raman 

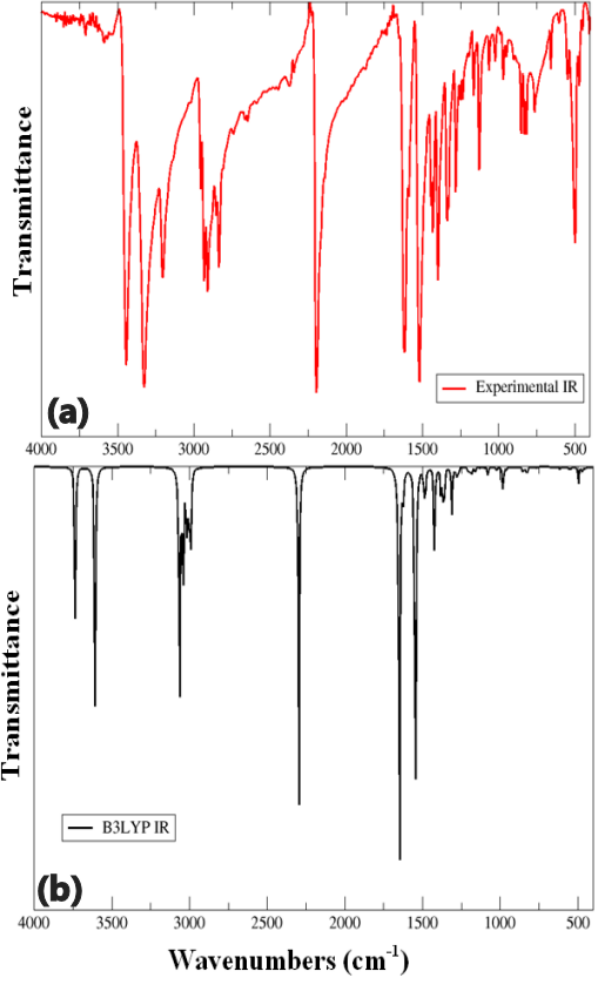

Fig. 2. Comparison of observed and calculated infrared spectra of the title compound.
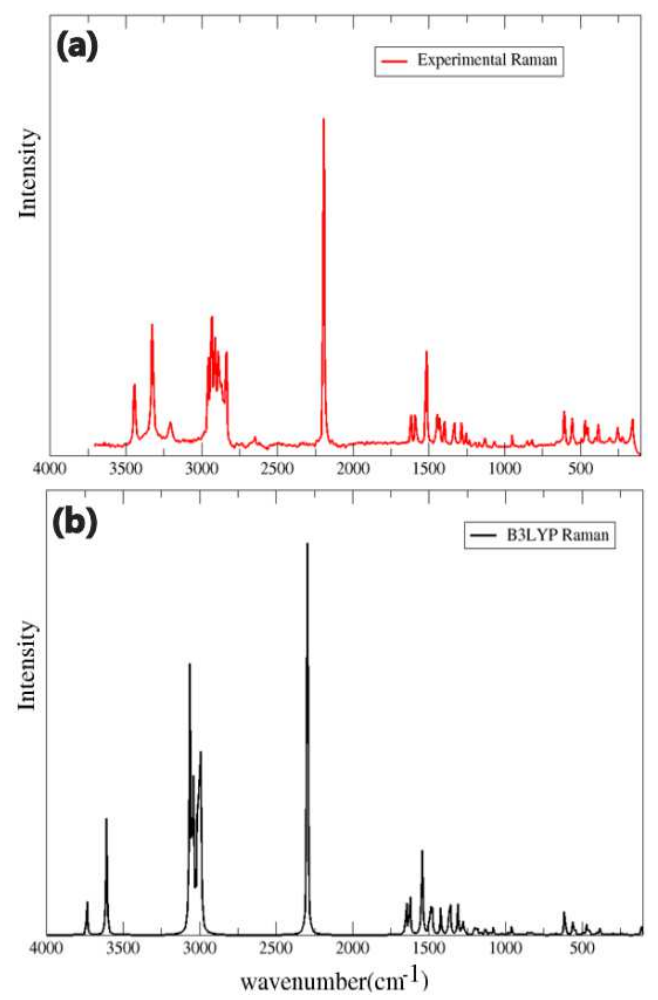

Fig. 3. Comparison of observed and calculated Raman spectra of the title compound. spectrum. These modes were not observed in FT-IR, and were calculated to be at $281 \mathrm{~cm}^{-1}$ and $153 \mathrm{~cm}^{-1}$ by scaled B3LYP method.

\subsubsection{Amino group vibrations}

In primary amines, usually the $\mathrm{N}-\mathrm{H}$ stretching vibrations occur in the region of $3500-3300 \mathrm{~cm}^{-1}$ [23-25]. The $\mathrm{NH}_{2}$ group has two vibrations; one is being asymmetric and other symmetric. The frequency of asymmetric vibration is higher than that of symmetric one. In the present study, the asymmetric and symmetric $\mathrm{NH}$ stretching vibrations were identified at $3445 / 3444 \mathrm{~cm}^{-1}$ (FT-IR/FT-Raman) and $3327 / 3326 \mathrm{~cm}^{-1}$ (FT-IR/FTRaman), respectively. The same bands were calculated to be at 3561 and $3439 \mathrm{~cm}^{-1}$ by scaled B3LYP/6$311++\mathrm{G}(\mathrm{d}, \mathrm{p})$ method. As expected, these two modes are pure stretching modes, as it is evident from PED column, they are contributing almost $100 \%$. It is also observed that, the asymmetric band is more intense than the symmetric one. These assignments are in line with the literature [26, 27].

The $\mathrm{N}-\mathrm{H}$ in-plane bending vibrations (scissoring) are usually observed in the region of $1610-1630 \mathrm{~cm}^{-1}$, rocking vibrations are assigned in the range of 1100$1200 \mathrm{~cm}^{-1}$ and the out of plane bending (wagging and twisting) vibrations are normally identified under $900 \mathrm{~cm}^{-1}$ [28-31]. In this case, in plane bending mode $\delta_{\mathrm{HNH}}$ was observed at $1616 / 1618 \mathrm{~cm}^{-1}$ (FT-IR/FTRaman) and was calculated to be at $1581 \mathrm{~cm}^{-1}$ by scaled B3LYP.

Similarly, in-plane rocking modes were observed at $1164 / 1168 \mathrm{~cm}^{-1}$ (FT-IR/FT-Raman), $1127 \mathrm{~cm}^{-1}$ (FTIR) and $1063 \mathrm{~cm}^{-1}$ (FT-IR), and these modes were calculated to be at $1153 \mathrm{~cm}^{-1}, 1137 \mathrm{~cm}^{-1}$ and $1084 \mathrm{~cm}^{-1}$ by scaled B3LYP method.

The $\mathrm{N}-\mathrm{H}$ out-of-plane bending modes were assigned to and observed at $657 \mathrm{~cm}^{-1}$ (FT-IR), $472 / 453 \mathrm{~cm}^{-1}$ (FTIR/FT-Raman). These modes were calculated to be at $644 \mathrm{~cm}^{-1}, 476 \mathrm{~cm}^{-1}, 281 \mathrm{~cm}^{-1}$ and $204 \mathrm{~cm}^{-1}$ by B3LYP method. According to the literature, these assignments agree well. The $\mathrm{N}-\mathrm{H}$ vibrations have not been affected by the vibrations of other substituents.

\subsubsection{Carbonitrile group vibrations}

Unsaturated or aromatic nitriles, in which the double bond or ring is adjacent to $\mathrm{C} \equiv \mathrm{N}$ group, absorb more strongly in infrared region than saturated compounds, and the related band occurs at somewhat lower frequency, near $2230 \mathrm{~cm}^{-1}$ [32]. In the present study, the computed value is assigned to the stretching of $\mathrm{C} \equiv \mathrm{N}$ group, and it is in a good agreement with our experimental spectrum; the observed band in FT-IR spectrum at $2197 \mathrm{~cm}^{-1}$ and $2196 \mathrm{~cm}^{-1}$ in FT-Raman spectrum. The vibrational mode calculated to be at $2189 \mathrm{~cm}^{-1}$ by scaled B3LYP methods is assigned to the in-plane stretching vibration of $\mathrm{C} \equiv \mathrm{N}$ group. In addition, in the carbonitrile group (C11-C20) $\nu_{\mathrm{C}-\mathrm{C}}$ mode has been observed at $2197 \mathrm{~cm}^{-1}$ in FT-IR and at $2196 \mathrm{~cm}^{-1}$ in FT-Raman spectra. This mode has been calculated to be at $2189 \mathrm{~cm}^{-1}$ by scaled B3LYP method. 


\subsubsection{Tetrahydrobenzo group vibrations}

The $\mathrm{CH}_{2}$ group has 24 vibrational modes (4 asymmetrical and 4 symmetrical stretching modes, 4 scissoring modes, 4 wagging modes, 4 twisting modes and 4 rocking modes). The asymmetric stretching $\mathrm{CH}_{2}$, symmetric stretching $\mathrm{CH}_{2}$, scissoring vibrations $\mathrm{CH}_{2}$, and the wagging vibration $\mathrm{CH}_{2}$ appear in the regions of $3000 \pm 20$, $2900 \pm 25,1440 \pm 10$ and $1340 \pm 25 \mathrm{~cm}^{-1}$, respectively $[33,34]$.

For our compound the $\mathrm{CH}_{2}$ asymmetric stretching modes are observed at $2956 \mathrm{~cm}^{-1}$ (FT-IR), $2930 / 2936 \mathrm{~cm}^{-1}$ (FT-IR/FT-Raman), $\quad 2909 / 2912 \quad \mathrm{~cm}^{-1} \quad$ (FT-IR/FTRaman) and $2889 \mathrm{~cm}^{-1}$ (FT-Raman). These asymmetric stretching modes have been calculated to be at $2924 \mathrm{~cm}^{-1}, 2921 \mathrm{~cm}^{-1}, 2908 \mathrm{~cm}^{-1}$ and $2897 \mathrm{~cm}^{-1}$ by the scaled B3LYP method.

Similarly, for our compound the $\mathrm{CH}_{2}$ symmetric stretching modes are observed at $2853 \mathrm{~cm}^{-1}$ (FT-IR) and $2836 / 2838 \mathrm{~cm}^{-1}$ (FT-IR/FT-Raman). These symmetric stretching modes have been calculated to be at $2879 \mathrm{~cm}^{-1}, 2872 \mathrm{~cm}^{-1}, 2863 \mathrm{~cm}^{-1}$ and $2854 \mathrm{~cm}^{-1}$ by the scaled B3LYP method.

The $\mathrm{CH}_{2}$ scissoring modes have been observed at 1444/1446 $\mathrm{cm}^{-1}$ (FT-IR/FT-Raman), $1433 \mathrm{~cm}^{-1}$ (FTIR), $1429 \mathrm{~cm}^{-1}$ (FT-Raman) and $1399 \mathrm{~cm}^{-1}$ (FT-IR). These scissoring modes have been calculated to be at $1439 \mathrm{~cm}^{-1}, 1429 \mathrm{~cm}^{-1}, 1426 \mathrm{~cm}^{-1}$ and $1417 \mathrm{~cm}^{-1}$.

The $\mathrm{CH}_{2}$ wagging modes have been observed at $1399 \mathrm{~cm}^{-1}$ (FT-Raman), 1339/1333 $\mathrm{cm}^{-1}$ (FT-IR/FTRaman) and $1330 \mathrm{~cm}^{-1}$ (FT-IR). These wagging modes have been calculated to be at $1363 \mathrm{~cm}^{-1}, 1324 \mathrm{~cm}^{-1}$, $1313 \mathrm{~cm}^{-1}$ and $1310 \mathrm{~cm}^{-1}$.

The $\mathrm{CH}_{2}$ twisting and rocking modes appear in the regions [33] of $1260 \pm 10$ and $800 \pm 25 \mathrm{~cm}^{-1}$. For our title compound, the $\mathrm{CH}_{2}$ twisting modes have been observed at $1251 / 1255 \mathrm{~cm}^{-1}$ (FT-IR/FT-Raman), $1235 \mathrm{~cm}^{-1}$ (FT-IR), $1197 \mathrm{~cm}^{-1}$ (FT-Raman), 1164/1168 $\mathrm{cm}^{-1}$ (FTIR/FT-Raman). These twisting modes have been calculated to be at $1256 \mathrm{~cm}^{-1}, 1228 \mathrm{~cm}^{-1}, 1216 \mathrm{~cm}^{-1}$ and $1153 \mathrm{~cm}^{-1}$ by scaled B3LYP.

Finally, the $\mathrm{CH}_{2}$ rocking modes have been observed at $971 \mathrm{~cm}^{-1}$ (FT-IR) and $852 / 851 \mathrm{~cm}^{-1}$ (FT-IR/FTRaman), these rocking modes have been calculated to be at $982 \mathrm{~cm}^{-1}, 879 \mathrm{~cm}^{-1}, 799 \mathrm{~cm}^{-1}$ and $737 \mathrm{~cm}^{-1}$ by scaled B3LYP method.

In the ring $\nu_{\mathrm{C} 4=\mathrm{C} 5}$ has been observed at $1590 / 1589 \mathrm{~cm}^{-1}$ (FT-IR/FT-Raman) and calculated to be at $1558 \mathrm{~cm}^{-1}$ by scaled B3LYP method. Other modes within the $\nu_{\mathrm{C}=\mathrm{C}}$ have been observed at $1164 / 1168 \mathrm{~cm}^{-1}$ (FT-IR/FT-Raman), $1063 \mathrm{~cm}^{-1}$ (FT-IR) and $1023 \mathrm{~cm}^{-1}$ (FT-IR). These modes have been calculated to be at $1153 \mathrm{~cm}^{-1}, 1084 \mathrm{~cm}^{-1}$ and $1034 \mathrm{~cm}^{-1}$ by scaled B3LYP method.

\subsection{NMR analysis}

The theoretical and experimental chemical shifts of ${ }^{13} \mathrm{C}$ and ${ }^{1} \mathrm{H}$ and the assignments of ATHBTCN is shown in Table II. The experimental ${ }^{13} \mathrm{C}$ and ${ }^{1} \mathrm{H}$ NMR spectra are presented in Fig. 4a and b. In recent years, gaugeincluding atomic orbital GIAO computational method is efficient in predicting chemical shifts of various organic compounds [35].

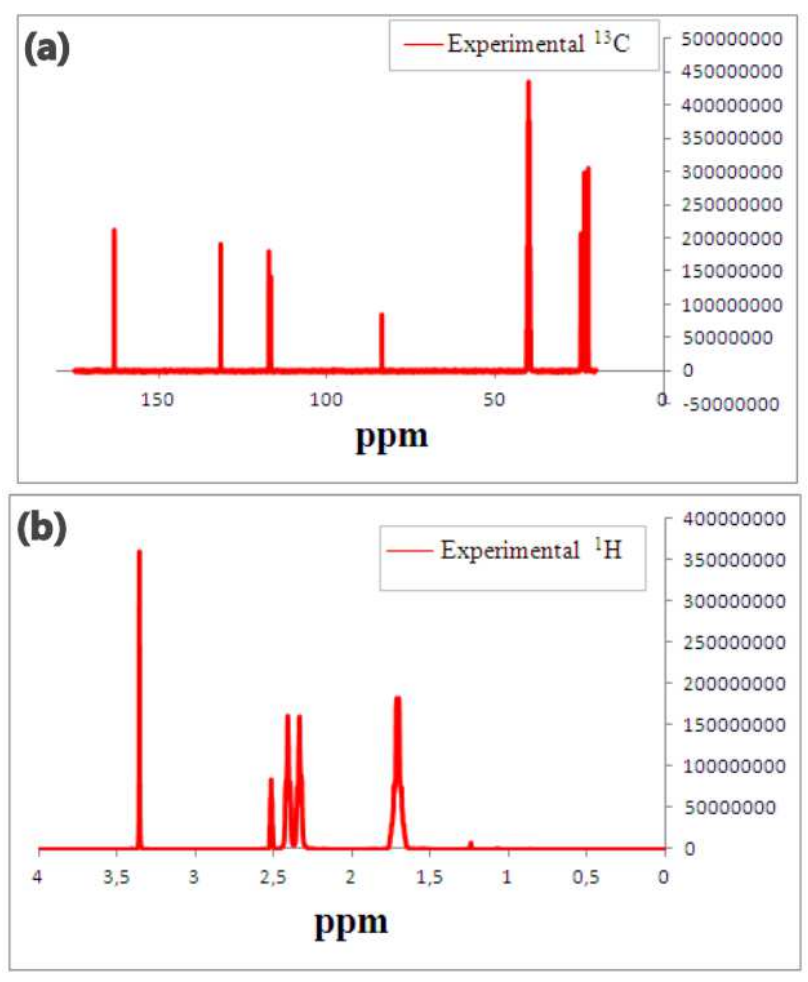

Fig. 4. The experimental ${ }^{13} \mathrm{C}$ and ${ }^{1} \mathrm{H}$ NMR spectra.

In this study, the optimized structure of ATHBTCN is used to calculate the NMR spectra by the DFT/B3LYP method with $6-311++\mathrm{G}(\mathrm{d}, \mathrm{p})$ level using the GIAO method. The result in Table III shows that the range of ${ }^{13} \mathrm{C}$ NMR chemical shift of the typical organic molecule usually is $>100 \mathrm{ppm}$ which ensures a reliable interpretation of spectroscopic parameters [36, 37]. In this study, ${ }^{13} \mathrm{C}$ NMR chemical shifts in the ring of the title molecule are $>100$ ppm, as was expected.

TABLE III

${ }^{13} \mathrm{C}$ and ${ }^{1} \mathrm{H}$ NMR shifts for ATHBTCN.

\begin{tabular}{c|c|c|c|c|c}
\hline \hline ATOM & $\begin{array}{c}\text { B3LYP } \\
{[\mathrm{ppm}]}\end{array}$ & $\begin{array}{c}\text { Exp. } \\
{[\mathrm{ppm}]}\end{array}$ & ATOM & $\begin{array}{c}\text { B3LYP } \\
{[\mathrm{ppm}]}\end{array}$ & $\begin{array}{c}\text { Exp. } \\
{[\mathrm{ppm}]}\end{array}$ \\
\hline $\mathrm{C}(1)$ & 26.36 & 24.49 & $\mathrm{H}(7)$ & 1.65 & 1.70 \\
$\mathrm{C}(2)$ & 28.01 & 39.58 & $\mathrm{H}(8)$ & 2.39 & 2.33 \\
$\mathrm{C}(3)$ & 28.39 & 39.98 & $\mathrm{H}(9)$ & 2.57 & 2.53 \\
$\mathrm{C}(4)$ & 129.75 & 117.29 & $\mathrm{H}(14)$ & 4.24 & 3.94 \\
$\mathrm{C}(5)$ & 139.91 & 131.58 & $\mathrm{H}(15)$ & 4.52 & 3.36 \\
$\mathrm{C}(6)$ & 29.17 & 40.20 & $\mathrm{H}(16)$ & 2.43 & 2.34 \\
$\mathrm{C}(10)$ & 170.72 & 163.23 & $\mathrm{H}(17)$ & 2.55 & 2.52 \\
$\mathrm{C}(11)$ & 88.49 & 83.68 & $\mathrm{H}(18)$ & 1.84 & 1.73 \\
$\mathrm{C}(20)$ & 118.95 & 116.67 & $\mathrm{H}(19)$ & 1.57 & 1.68 \\
& & & $\mathrm{H}(22)$ & 1.8 & 1.71
\end{tabular}




\subsection{UV analysis}

On the basis of fully optimized ground-state structure, the TD-DFT-B3LYP-6311++G(d,p) method was used to determine the low-lying excited states of ATHBTCN. The calculated excitation energies, oscillator strength $f$ and wavelength $\lambda$ and spectral assignments were carried out and compared with measured experimental wavelengths, given in Table IV.

According to the calculation results, three sharp electronic transitions were observed for title molecule (274, 277, $310 \mathrm{~nm}$ for ATHBTCN in DMSO), in good agreement with the measured experimental data, as shown in Fig. 5. According to Frank-Condon principle, the maximum absorption peaks correspond in an UVvisible spectrum to vertical excitation [36].

TABLE IV

Excitation energies for ATHBTCN.

\begin{tabular}{c|c|c|c|c|c}
\hline \hline$\lambda_{\text {cal. }}$ & $\lambda_{\text {exp. }}$ & $E[\mathrm{eV}]$ & $f$ & Assignment & Major contribution \\
\hline 310 & & 3.9969 & 0.0011 & $n \rightarrow \pi^{*}$ & HOMO $\rightarrow$ LUMO +1 \\
277 & 290 & 4.4690 & 0.1040 & $\pi \rightarrow \pi^{*}$ & HOMO $\rightarrow$ LUMO \\
274 & & 4.5181 & 0.0084 & $n \rightarrow \pi^{*}$ & HOMO $\rightarrow$ LUMO +2
\end{tabular}
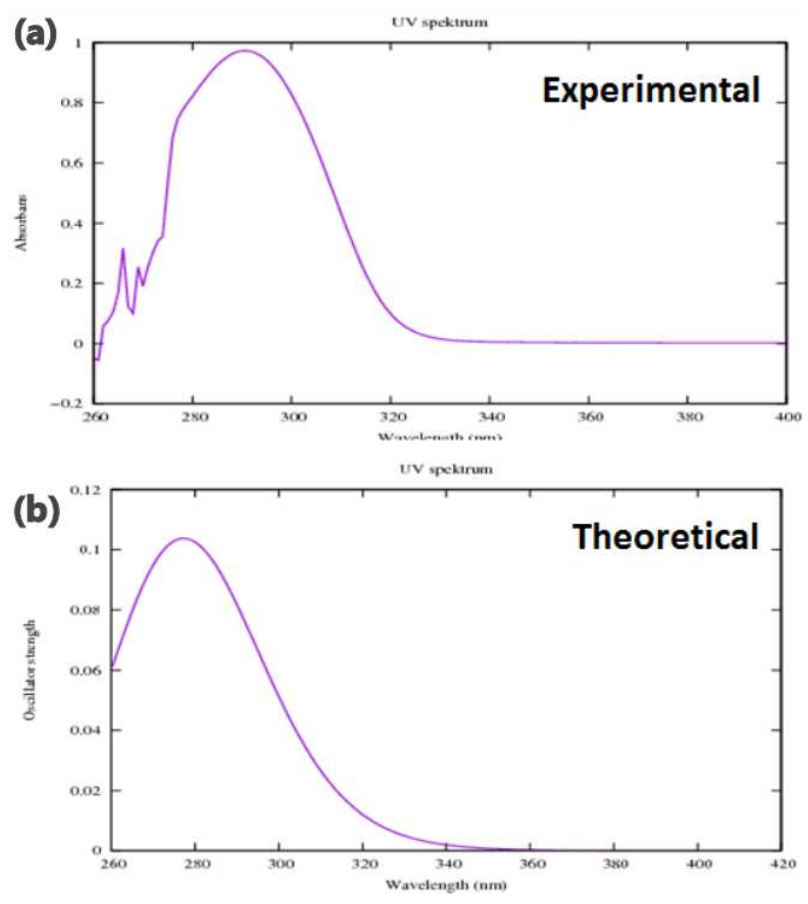

Fig. 5. Experimental and theoretical UV spectrum of ATHBTCN.

\section{Conclusions}

In this study, the vibrational analysis of ATHBTCN molecule was carried out using experimental FT-IR spectroscopy, and theoretical calculations (DFT/B3LYP method). The optimized geometric parameters, vibrational harmonic frequencies and PED assignments for the compound have been calculated using DFT/B3LYP method with $6-311++\mathrm{G}(\mathrm{d}, \mathrm{p})$ basis set. The theoretical optimized geometric parameters (bond lengths and angles) and vibrational frequencies were compared with the experimental data. Considerable level of correlation has been noticed. The detailed PED analysis of the compound has shown a good agreement with the experimental data. Besides, the ${ }^{13} \mathrm{C} \mathrm{NMR}$ and ${ }^{1} \mathrm{H}$ NMR chemical shifts and UV spectra were obtained by the DFT/B3LYP methods, using $6-311++\mathrm{G}(\mathrm{d}, \mathrm{p})$ basis set, in accordance with experimental results.

\section{Acknowledgments}

Authors would like to extend their appreciation to Scientific Research at Suleyman Demirel University for funding this research through the research project 3555YL2-13.

\section{References}

[1] W.L. Silva, M.C. Lima, S.L. Galdino, I.R. Pitta, C.A. Simone, Acta Cryst. E67, o3161 (2011).

[2] J.D. Magdaline, T. Chithambarathanu, J. Appl. Chem. 8, 6 (2015).

[3] J.L. Reddinger, J.R. Reynolds, Adv. Polym. Sci. 145, 57122 (1999).

[4] D.T. McQuade, A.E. Pullen, T.M. Swager, Chem. Rev. 100, 2537 (2000).

[5] I.C. Choong, W. Lew, D. Lee, P. Pham, M.T. Burdett, J.W. Laam, C. Wiesmann, T.N. Luong, B. Fahr, W.L. DeLano, R.S. McDowell, D.A. Allen, D. Erlanson, E.M. Gordon, T. O'Brien, J. Med. Chem. 45, 5005 (2002).

[6] K. Dore, S. Dubus, H.A. Ho, I. Levesque, M. Brunette, G. Corbeil, M. Boissinot, G. Boivin, M.G. Bergeron, D. Boudreau, M. Leclerc, J. Am. Chem. Soc. 126, 4240 (2004).

[7] D.K. James, J.M. Tour, Topics Curr. Chem. 257, 33 (2005).

[8] P. Si, Q. Chi, Z. Li, J. Ulstrup, P.J. Moller, J. Mortensen, J. Am. Chem. Soc. 129, 3888 (2007).

[9] Merck Index, 13th ed., Merck \& Co, Whitehouse Station, New Jersery 2001.

[10] J. Bakker, F.J. Gommers, I. Nieuwenhius, H. Wynberg, J. Biol. Chem. 254, 1841 (1979).

[11] S. Iyengar, J.T. Arnason, B.J.R. Philogene, P. Morand, N.H. Werstiuk, G. Timmins, Pesticide Biochem. Physiol. 29, 1 (1987).

[12] H. Matsuura, G. Saxena, S.W. Farmer, R.E.W. Hancock, G.H. Towers, Planta Med. 62, 256 (1996).

[13] G.F.Q. Chan, G.H.N. Towers, J.C. Mitchell, Phytochem. 14, 2295 (1975).

[14] J.B. Hudson, E.A. Graham, N. Miki, G.H.N. Towers, L.L. Hudson, R. Rossi, A. Carpita, D. Neri, Chemosphere 19, 1329 (1989). 
[15] J. Malmstrom, M. Jonsson, I.A. Cotgreave, L. Hammarstrom, M. Sjodin, L. Engmann, J. Am. Chem. Soc. 123, 3434 (2001).

[16] M.J. Frisch, G.W. Trucks, H.B. Schlegel, G.E. Scuseria, M.A. Robb, J.R. Cheeseman, G. Scalmani, V. Barone, B. Mennucci, G.A. Petersson, H. Nakatsuji, M. Caricato, X. Li, H.P. Hratchian, A.F. Izmaylov, J. Bloino, G. Zheng, J.L. Sonnenberg, M. Hada, M. Ehara, K. Toyota, R. Fukuda, J. Hasegawa, M. Ishida, T. Nakajima, Y. Honda, O. Kitao, H. Nakai, T. Vreven, J.A. Montgomery Jr., J.E. Peralta, F. Ogliaro, M. Bearpark, J.J. Heyd, E. Brothers, K.N. Kudin, V.N. Staroverov, R. Kobayashi, J. Normand, K. Raghavachari, A. Rendell, J.C. Burant, S.S. Iyengar, J. Tomasi, M. Cossi, N. Rega, J.M. Millam, M. Klene, J.E. Knox, J.B. Cross, V. Bakken, C. Adamo, J. Jaramillo, R. Gomperts, R.E. Stratmann, O. Yazyev, A.J. Austin, R. Cammi, C. Pomelli, J.W. Ochterski, R.L. Martin, K. Morokuma, V.G. Zakrzewski, G.A. Voth, P. Salvador, J.J. Dannenberg, S. Dapprich, A.D. Daniels, Ö. Farkas, J.B. Foresman, J.V. Ortiz, J. Cioslowski, D.J. Fox, Gaussian 09, revision A.1. Gaussian, Inc., Wallingford CT 2009.

[17] N. Sundaraganesan, S. Ilakiamania, H. Saleema, P.M. Wojciechowski, D. Michalska, Spectrochim. Acta Part A 61, 2995 (2005).

[18] R. Dennington, T. Keith, J. Millam, Gaussviev Ver. 5. s.l.: Semichem Inc. Shawnee Mission, KS 2009.

[19] M.H. Jamróz, Vibrational Energy Distribution Analysis, VEDA 4 Computer Program, Warsaw 2004.

[20] C.I. Sainz-Diaz, M. Francisco-Marquez, A. VivierBunge, Theor. Chem. Acc. 125, 83 (2010).

[21] T.D. Klots, R.D. Chirico, W.V. Steele, Spectrochim. Acta Part A 50, 765 (1994).

[22] M. Karabacak, M. Çınar, M. Kurt, J. Mol. Struct. 968, 108 (2010)

[23] Y. Wang, S. Saebo, C.V. Pittman, J. Mol. Struct. (THEOCHEM) 281, 91 (1993).
[24] S. Sudha, N. Sundaraganesan, M. Kurt, M. Cinar, M. Karabacak, J. Mol. Struct. 985, 148 (2011).

[25] N. Puviarasan, V. Arjunan, S. Mohan, Turkey J. Chem. 26, 323 (2002).

[26] M. Karabacak, M. Kurt, A. Ataç, J. Phys. Organic Chem. 22, 321 (2009).

[27] A. Usha Rani, N. Sundaraganesan, M. Kurt, M. Cinar, M. Karabacak, Spectrochim. Acta Part A 75, 1523 (2010)

[28] H.F. Hameka, J.O. Jensen, J. Mol. Struct. (THEOCHEM) 362, 325 (1996).

[29] J.R. During, M.M. Bergana, H.V. Phan, J. Raman Spectroscopy 22, 141 (1991)

[30] G. Varsanyi, Vibrational Spectra of Benzene Derivatives, Academic Press, New York 1969.

[31] Z. Niu, K.M. Dunn, J.E. Boggs, J. Mol. Phys. 55, 421 (1985).

[32] J.B. Labbert, H.F. Shurvel, L. Verbit, R.G. Cooks, G.H. Stout, Organic Structural Analysis, Macmillan Publ. Co. Inc., New York 1976.

[33] N.P.G. Roeges, A Guide to the Complete Interpretation of Infrared Spectra of Organic Structures, Wiley, New York 1994.

[34] N.B. Colthup, L.H. Daly, S.E. Wiberly, Introduction to Infrared and Raman Spectroscopy, 3rd ed., Academic Press, Boston 1990.

[35] R.K. Alan, G.A. Novruz, D. Jacek, P.M. Prabhu, C.H. Dennis, G. Alâattin, Magnetic Resonance Chem. 45, 532 (2007).

[36] D. Shoba, S. Periandi, S. Boomadevi, S. Ramalingam, E. Fereyduni, Spectrochim. Acta Part A 118, 438 (2014).

[37] M. Karabacak, Z. Cinar, M. Kurt, S. Sudha, N. Sundaraganesan, Spectrochimica Acta Part A 85, 179 (2012). 